\title{
Determinants of Adherence to Medications in Geriatrics in Serse Elian City , Menoufia Governorate , Egypt .
}

\author{
Aml A. Salama*, Abd El Rahman A. Yasin **, Walaa Elbarbary*** \\ * family medicine department , Faculty of medicine, Menoufia University, \\ Egypt . \\ ** clinical pharmacology, Faculty of medicine, Menoufia University , Egypt . \\ **** family medicine, Ministry Of Health, Egypt.
}

Received : December, 2015 accepted : March 2016

\begin{abstract}
Background: Adherence to therapies is a corner stone of treatment success. Medication non adherence in geriatric patients leads to substantial worsening of disease, increased health care costs and death. A variety of factors are likely to affect adherence. Barriers to adherence could be addressed for each patient to deal with. Objective: To assess the determinant factors of medication adherence in old patients living in their own houses. Methods: This is a cross-sectional study of random sample of 438 geriatric patients where aged 70-85 years -old, living in their own homes in Serse Elian City, Menoufia Governorate . Patients' information were collected from the prescriptions in the file of the patient and home visits were done to examine their daily drug consumption.

Results: Male geriatric patient were found to be more adherent to their medications than female (63.9 \% versus $36.1 \%$ ). Functional complain, living alone, low perceived health, cognitive impairment and patients satisfaction of their management plan were found to be significant factors in restrict following their prescribed drugs.

Conclusions: Medication non adherence is not a rare event in elderly patients and is associated with functional complains and cognitive impairment.
\end{abstract}

Key words : Adherence, Geriatric, Medications.

Corresponding author: Dr. Aml Ahmed Salama E mail : aml_salama2002@yahoo.com

\section{Introduction}

Adherence has been defined as the "active, voluntary, and collaborative involvement of the patient in a mutually acceptable course of behavior to produce a therapeutic result ${ }^{(1)}$. This definition implies that the patient has a choice and that both patients and providers mutually establish treatment goals and the medical regimen (1). Medication adherence usually refers to whether patients take their medications as prescribed (eg, twice daily), as well as whether they continue to take a prescribed medication
(2). Medication adherence behavior has thus been divided into 2 main concepts, namely ,adherence and persistence. Although conceptually similar, adherence refers to the intensity of drug use during the duration of therapy, whereas persistence refers to the overall duration of drug therapy ${ }^{(3)}$.

Rates of adherence for individual patients are usually reported as the percentage of the prescribed doses of the medication actually taken by the patient over a specified period. Some 
investigators have further refined the definition of adherence to include data on dose taking (taking the prescribed number of pills each day) and the timing of doses (taking pills within a prescribed period). Adherence rates are typically higher among patients with acute conditions, as compared with those with chronic conditions; persistence among patients with chronic conditions is disappointingly low, dropping most dramatically after the first six months of therapy ${ }^{(4)}$.

Measures to facilitate patient medication adherence should be considered an integral part of the comprehensive care of older patients with multiple diseases. However, impairment of cognitive functions and dementia, in particular, may substantially compromise adherence behavior. Therefore, a literature review was performed to identify factors associated with adherence to medication in patients with cognitive impairment or dementia, and to discuss strategies for improvement of non-adherence ${ }^{(5)}$.

Elderly patients' adherence to prescribed medications is a complex phenomenon that depends on an interaction of sociodemographic, medication, and psychological factors. In previous studies, factors attributed to nonadherence included access to medicines, polypharmacy, multiple morbidity , complexity of regimens, as well as poor communication between prescriber and patient. Some predictors of adherence are modifiable, such as depression, medication knowledge, health literacy, and self-efficacy ${ }^{(6)}$.

Medication factors related to adherence include the characteristics of the medication (eg, dosing frequency or presence of side effects). Personal factors that affect adherence include: personal beliefs about the condition for which the medication is prescribed (eg, how serious the condition is and how likely the medication is to have a positive effect). Individual cognitive abilities, including memory, overall intellectual ability, organization skills, and health literacy. Health literacy has emerged as an important factor that affects older persons' capacity, for example, to make health care choices ${ }^{(7)}$.

Economic factors pertinent to medication adherence include whether patients have insurance or other financial resources to pay for the medication. Patients' relationship with their physician as well as the physician's communication style can affect adherence $^{(8)}$.

\section{Subject and Methods}

The present study is a cross section study of a random sample which was taken from health records of the patients. The Each 3rd elderly persons (438 geriatric) was included in the study (aged 70-85 years old) during their monthly follow up visits for chronic diseases as diabetes, hypertension,... ect to the primary health care center. Those patients were living in their own homes in Serse Elian City of Menuofia Governorate . Exclusion criteria included patients had an active psychotic illness which makes them unable to give informed consent and interfere with their own judgment. Human rights and ethical considerations were followed during the study with total confidentiality of any obtained data. The Menoufia faculty of medicine committee for medical ethics of research formally approved the study before it began. A written consent form was taken from all participants after explaining the aim of the study. The 
study was conducted during the period of six months from the beginning of April to the end of September 2014 .

Information on the intake of all drugs were collected from patients' family records in the selected family health centre (the only primary health care in the Sers Elian city ) . Detailed information were collected from the prescription in the file of the patient before visiting him at home. The subjects were followed at their homes after 2-3 weeks of their follow up visits in primary health care center, and examined their daily drug consumption. Their drug storage were examined .The data from patients: age - gender education, occupation and their socio economic standard according to Elgelany , 2012(9) were assessed and calculated as low, middle and high . The subjects were asked about dose, the real frequency of use, and time of intake. The risk of inappropriate prescribed drug use were assessed through reporting the medication used by older patients after 2-3 weeks and compared it with doctors' perceived medication regimens for their patients.

\section{The method of calculating adherence-} scores (10) : For each participant adherence scores were calculated based on observations of the participants' actual use of drugs (examine their drug storage by counting the remaining pills and ask the old patient about their actual use) and compare it to the information given by the prescription of the family physician. The drug score was based on the ratio of the number of prescribed drugs used by the participants to the number of drugs prescribed by the family physician. Ratios below 0.8 were scored as deviating, above 0.8 as not deviating .Two scores were calculated, the dose score was based on daily doses that agreed with the physicians' information, the regimen score was based on the adherence to the regimen prescribed for a particular drug (once daily, twice daily, etc.). The studied groups divided in to two groups, adherent and non adherent (score below 0.8 ) to study the possible determinants of that adherence to medication in geriatrics.

The determinants of drug adherence were assessed through pre-designed questionnaire filled by the researcher after explaining each question for the patient in easy language to detect the determinant of adherence to their medications . Validation of the questionnaire was performed by conducted a pilot study using a structured interview to test reliability of the questions (by interviewing 20 old patient according to inclusion and exclusion criteria from the same area of the research) \& modifications to questions were applied according to the feedback of participants. They were asked if they live alone or with other family member, if they lost their partner or not, if they complained low perceived health and their reported diagnosis. Patients also were asked about their satisfactions regarding their medications .Three points were given to the patient who answer "yes I feel satisfied about my drugs ", two points were given to the patient who answered that he is satisfied to some extant while one point was given to unsatisfied patient. The patients were asked if they found any difficulty in performing their activity of daily living as feeding themselves, bathing and instrumental activity of daily living as driving and turn on instruments at home. Psychological complains as depressed mood and law perceived health . They 
also reported the number of chronic health problems they suffered. Medications parameters as price of the drug, number of prescribed medications and type of health insurance they deal with were reported.

Mental status of the studied group was assessed using Scoring of Mini COG ${ }^{(11}$ ,12) : three items recall test (TIR) screener names 3 unrelated objects (ex:

banana/sunrise/chair); patient repeated them back. Patient is told that , they were asked to recall the words in two minutes.

\section{Statistical Analysis}

The data were tabulated and analyzed by Statistical Package of Social Science program (SPSS) version 20 using personal computer. Quantitative data was expressed as mean and standard deviation $(\mu \pm$ SD) and analyzed by Student $t$ - test for comparison of two groups of normally distributed variables. Qualitative data was expressed as number and percentage and analyzed by Chi-square test. Level of significance was set at $\mathrm{P}<0.05$.

\section{Results}

The sample size consisted of 438 geriateric patients who lived alone in their houses in Sers Elian city, Menoufia Governorate. According to their adherence to their medications ,they divided into two groups ,adherents $(73.2 \%)$ and non adherents groups ( $26.8 \%$ ) figure (1) .

Mean of age of patients was lower in adherent group $73.33 \pm 3.35$ than that of non adherent group 74.55 \pm 3.71 . This was statistically significant . Males constituted higher percentage of adherent group than females ( $64 \%$ are male versus $36 \%$ females ). Sex constituted statistically significant determinant of adherence . Education, and socioeconomic stander constituted non statistical significant difference in adherence of geriatric to medications .Retired employers constituted about half of adherent group while patients with non specified work in the past constituted about $47.9 \%$ of non adherent group. This difference constituted statistical significant difference (Table 1).

Functional activity of the patients as instrumental activity of daily living, basic activity of daily living and failure in getting up constituted a highly statistically significant difference( $\mathrm{p}$ value $<0.01$ ) in adherence to medications . Patients who had no difficulty in performing daily activity and getting up from beds at the morning, constituted higher percentage of adherent groups. Psychological complains as depressed mood shows statistically significant effect on medications adherence. Low perceived health and living alone show statistically significant effect on medication adherence in studied old patients while loss of their partner don't . As regarding number of health problem, having more than one chronic complains constituted no statistical significant determinant of adherence among groups Mini mental state was measured for each patient, a score was given for each patient according to their ability to recall three word after sometime which constituted a statistical significant difference between adherent and non adherent group (Table 2).

Medications parameters as price of the drugs , number of prescribed drugs and presence of health insurance constitute statistically significant determinant for 
adherence to medications in the studied old patients (Table 3) .

Patient satisfaction regarding their medication was higher among adherent group (Fig: 2)

\section{Discussion}

Medication non-adherence lowers treatment effectiveness, and is thus a very important problem in the management of patients with chronic diseases requiring long-term treatments. For calculating adherence-scores for each participant based on observations of the participants' actual use of drugs and information given by the prescription of the family physician. About 321 and 117 patients $(73 \%$ and $27 \%$ ) were classified as adherent and non adherent respectively to their prescribed medication . Another study (13) reported higher rate $(81 \%)$ of medication adherence to their medications . To detect the factors affecting adherence to their medication , the study compared the two groups (Adherent and non adherent group . As regarding socio-demographic data, sex of the patient and previous occupations constituted statistical significant difference between adherent and non adherent group while education, socioeconomic stander constituted non significant difference . Espino et al., ${ }^{(14)}$ reported that female patients were adherent more than males. Another study (15) reported that adherence was significantly high in the group with a low financial level. Another study (16) reported that the higher the education level, the higher the adherence of diabetes patients.

This study shows a statistical significant correlation of three items recall score of
Mini Mental State Examination score which was positively correlated to the adherence score . Kim et al., ${ }^{(17)}$ reported that higher Mini Mental Status Examination score was associated with high level medication adherence.

The present study shows that functional complains as difficulty in performing basic activity of daily living , instrumental activity of daily living and failure of getting up constituted highly statistical significant difference between adherent and non adherent groups. Epsio et al., ${ }^{(14)}$ reported that activity of daily living dependency as one of factor associated with prescription medication usage . Another study done in Germany (18) , reported that dependency on instrumental activities of daily living, low subjective health and medication disagreement between doctors and patients were predictors for polypharmacy and nod adherence to prescribed medications .

Psychological complains as depressed mode, feeling loneliness due to living alone and low perceived health shows statistical significant difference among adherent and non adherent groups . While, loss of partner and number of health problems constituted no significant difference among them . A study (19) reported that unmarried subjects, those with $>/=1$ chronic diseases and high depressive symptoms, were more likely to have non adherence to appropriate drugs . Baret et al., (10) reported that persons living alone were more prone to medication errors

A study ${ }^{(20)}$ reported that female sex, advanced age, number of chronic diseases and number of medications taken all significantly increased the 
likelihood of receiving potentially inappropriate medications as type of bad adherence to prescribed drugs in geriatric patients.

As regarding medications parameters as number of medication, price of all received drugs and having health insurance to cover the cost of the prescribed drugs, these factors constituted statistical significant difference among adherent and non adherent groups . According to Kim et al. (17) , a cause of low medication adherence among old patients is having to take multiple medications while another study (13) reported no association between medication numbers and adherence. A study (15) reported that private clinic cases, the adherence with medication of 1 drug per day was higher than with more than 2 drugs in old patients. In a study done in Brazile (21), non-adherence proved to be lower when the drugs were not available from the public healthcare network.

\section{Conclusion :}

In the present study, correlations were found between adherence to treatment in geriatric patients and their sex, age, functional complaint, feeling loneliness , low perceived health , cognitive impairment and satisfaction towards management plan. Different strategies should be used to increase medication adherence in geriatric patients to achieve better outcome in their health status .

\section{Recommendations}

Comprehensive assessment of the individual patient and careful consideration of all potential patient characters will probably help facilitate adherence and patients should be encouraged to visit their GP to follow up their drug adherence.

Identifying specific barriers for each patient and adopting suitable techniques to overcome them will be necessary to improve medication adherence.

\section{References}

1) Delamater AM. Improving patient adherence. Clin Diabetes. 2006 ; 24: 7177.

2) Caetano PA, Lam JM, Morgan SG. Toward a standard definition and measurement of persistence with drug therapy: examples from research on statin and antihypertensive utilization. Clin Ther. 2006 ; 28: 1411-1424.

3) Cramer JA, Roy A, Burrell A, Fairchild CJ, Fuldeore MJ, Ollendorf DA, Wong PK. Medication compliance and persistence: terminology and definitions. Value Health. 2008 ; 11: 4447.

4) Jackevicius CA, Mamdani M, Tu JV: Adherence with statin therapy in elderly patients with and without acute coronary syndromes. JAMA 2002;288:462-7.

5) Arlt S, Lindner R, Rösler A, von Renteln-Kruse W.Adherence to medication in patients with dementia: predictors and strategies for improvement. Drugs Aging 2008 ; 25(12):1033-47.

6) Soo Kyoung Lee, Bo-Yeong Kang, , Hong-Gee Kim, and Youn-Jung. Predictors of Medication Adherence in Elderly Patients with Chronic Diseases Using Support Vector Machine Models. Healthc Inform Res 2013 ; 19(1): 33-41. 
7) Finucane ML, Slovic $P$, Hibbard JH, Peters E, Mertz DK, McGregor DG. Aging and decision-making competence: An analysis of comprehension and consistency skills in older versus younger adults considering health plan options. J Behav Decis Making 2002; 15(2):141-64.

8) Bultman DC, Svarstad BL. Effects of physician communication style on client medication beliefs and adherence with antidepressant treatment. Patient Educ Couns 2000; 40(2):173-85.

9) El-Gilany A, El-Wehady A and ElWasify $\mathbf{M}$.Updating and validation of the socioeconomic status scale for health research in Egypt. EMHJ $2012 ; 18$ (9) .

10) Barat $I$, Andreasen $F$, and Damsgaard EMS :Drug therapy in the elderly: what doctors believe and patients actually do.Br J Clin Pharmacol. 2001; 51(6): 615-622.

11) Folstein MF, Folstein SE, McHugh PR. "Mini-mental state". A practical method for grading the cognitive state of patients for the clinician.J Psychiatr Res. 1975; 12:189-198.

12) Borson $S$, et al. Simplifying detection of cognitive impairment: Comparison of the Mini-Cog and MiniMental State Examination in a multiethnic sample. J Am Geriatr Soc 2005;53(5):871-4.

13) Kang-Ting Tsai, Jen-Hau Chen, Chiung-Jung Wen, Hsu-Ko Kuo, IShu Lu, Lee-Shu Chiu, Shwu-Chong Wu and Ding-Cheng Chan : Medication Adherence Among Geriatric Outpatients Prescribed Multiple Medications .Ameican Journal of Geriateric Pharmacotherapy 2010 ; (10)1 : 61-86.

14) Espino DV, Lichtenstein MJ, Hazuda HP, Fabrizio D, Wood RC, Goodwin J, Stroup-Benham CA, Markides KS.Correlates of prescription and over-the-counter medication usage among older Mexican Americans: the Hispanic EPESE study. Established Population for the Epidemiologic Study of the Elderly. J Am Geriatr Soc. 1998; 46(10):1228-34.

15) Kyung-Ae Park, Jung-Guk Kim, Bo-Wan Kim, Sin Kam, Keon-Yeop Kim, Sung-Woo Ha, and Sung-Taek Hyun : Factors that Affect Medication Adherence in Elderly Patients with Diabetes Mellitus. Korean Diabetes J. 2010 ; 34(1): 55-65.

16) Diehl AK, Bauer RL, Sugarek NJ. Correlates of medication compliance in non-insulin-dependent diabetes mellitus. South Med J 1987; 80:332-5.

17) Kim MO, Kim JH, Kim JE, Park BR, Lee JW, Park HG, Son HJ, Shin KW, Kim DG. Degree of compliance with polypharmacy and its influential factors in rural elderly patients with chronic diseases in South Korea. J Korean Acad Fam Med 2008; 29:60411.

18) Junius-Walker U, Theile G, Hummers-Pradier E: Prevalence and predictors of polypharmacy among older primary care patients in Germany. Fam Pract. 2007 ; 24(1):14-9. Epub 2006 Dec 11.

19) Raji MA, Ostir GV, Markides KS, Espino DV, Goodwin JS. Potentially inappropriate medication use by elderly Mexican Americans. Ann Pharmacother. 2003 ; 37(9):1197-202.

20) Lin HY, Liao CC, Cheng SH, Wang PC, Hsueh YS:Association of potentially inappropriate medication use with adverse outcomes in ambulatory elderly patients with chronic diseases: 
experience in a Taiwanese medical setting. Drugs Aging. 2008 ;25(1):49-59.

21) Antônio Augusto Schmitt Júnior, Stéphanie Lindner, Ernani Tiaraju de
Santa Helena: Assessment of adherence in elderly patients in primary care. Rev. Assoc. Med. Bras $2013 ; 59$ (6) . 
Table (1) : Demographic data as determinants of drug adherence among geriatric Patients

\begin{tabular}{|c|c|c|c|c|c|}
\hline & \begin{tabular}{|l|} 
Group (1) \\
Adherent \\
Group \\
$(\mathbf{N = 3 2 1})$ \\
$\mathrm{N} \quad(\%)$ \\
\end{tabular} & $\begin{array}{l}\text { Group (2) } \\
\text { Non -Adherent } \\
\text { Group } \\
(\mathbf{N}=117) \\
\text { N } \quad(\%)\end{array}$ & $\begin{array}{l}\text { Total } \\
\mathbf{N}=\mathbf{4 3 8} \\
\mathrm{N} \quad(\%)\end{array}$ & $\mathbf{X}^{2}$ & $P$ value \\
\hline $\begin{array}{l}\text { Sex } \\
\text { Male } \\
\text { Female } \\
\text { Age } \\
\text { Mean } \pm \text { SD } \\
\text { Education } \\
\text {-Illiterate } \\
\text {-Basic } \\
\text { - Secondary } \\
\text {-University } \\
\text { Occupation } \\
\text {-No work } \\
\text {-Unskilled worker } \\
\text {-Skilled worker } \\
\text {-Retired Employer } \\
\text { Socio-economic } \\
\text { Score } \\
\text {-High } \\
\text { - Middle } \\
\text { - Low }\end{array}$ & \begin{tabular}{|ll}
205 & $(64)$ \\
116 & $(36)$ \\
& \\
73.33 & \\
& \\
& \\
& \\
125 & $(38.9)$ \\
77 & $(24)$ \\
71 & $(21.1)$ \\
48 & $(15)$ \\
& \\
96 & $(29.9)$ \\
33 & $(10.3)$ \\
29 & $(9)$ \\
163 & $(50.8)$
\end{tabular} & $\begin{array}{ll}52 & (44.4) \\
65 & (55.6) \\
& \\
74.55 \pm 3.71 \\
\\
59 & (50.4) \\
21 \quad(17.9) \\
28 & (22.2) \\
9 & (7.7) \\
& \\
56 & (47.9) \\
4 & (3.4) \\
5(4.3) \\
52 & (44.4) \\
& \\
48 & \\
48 & (41) \\
31 & (26.5) \\
38 & (32.5)\end{array}$ & $\begin{array}{ll}257 & (58.7) \\
181 & (41.3) \\
& \\
73.66 \pm 3.8 \\
\\
184 \quad(42) \\
98 \quad(22.4) \\
99 \quad(22.6) \\
57 \quad(13) \\
\\
152(34.7) \\
37(8.4) \\
34(7.8) \\
215(49.1)\end{array}$ & \begin{tabular}{|l}
13.35 \\
$3.49^{* *}$ \\
7.68
\end{tabular} & $\begin{array}{l}<0.001^{*} \\
0.001^{*} \\
0.053\end{array}$ \\
\hline
\end{tabular}

$* \mathrm{p}$ value significant at $<0.05$.

** $\mathrm{t}$ test

Adherence Rat $73.3 \%$ 
Table (2) : Patients characters as determinants of drug adherence in geriatrics :

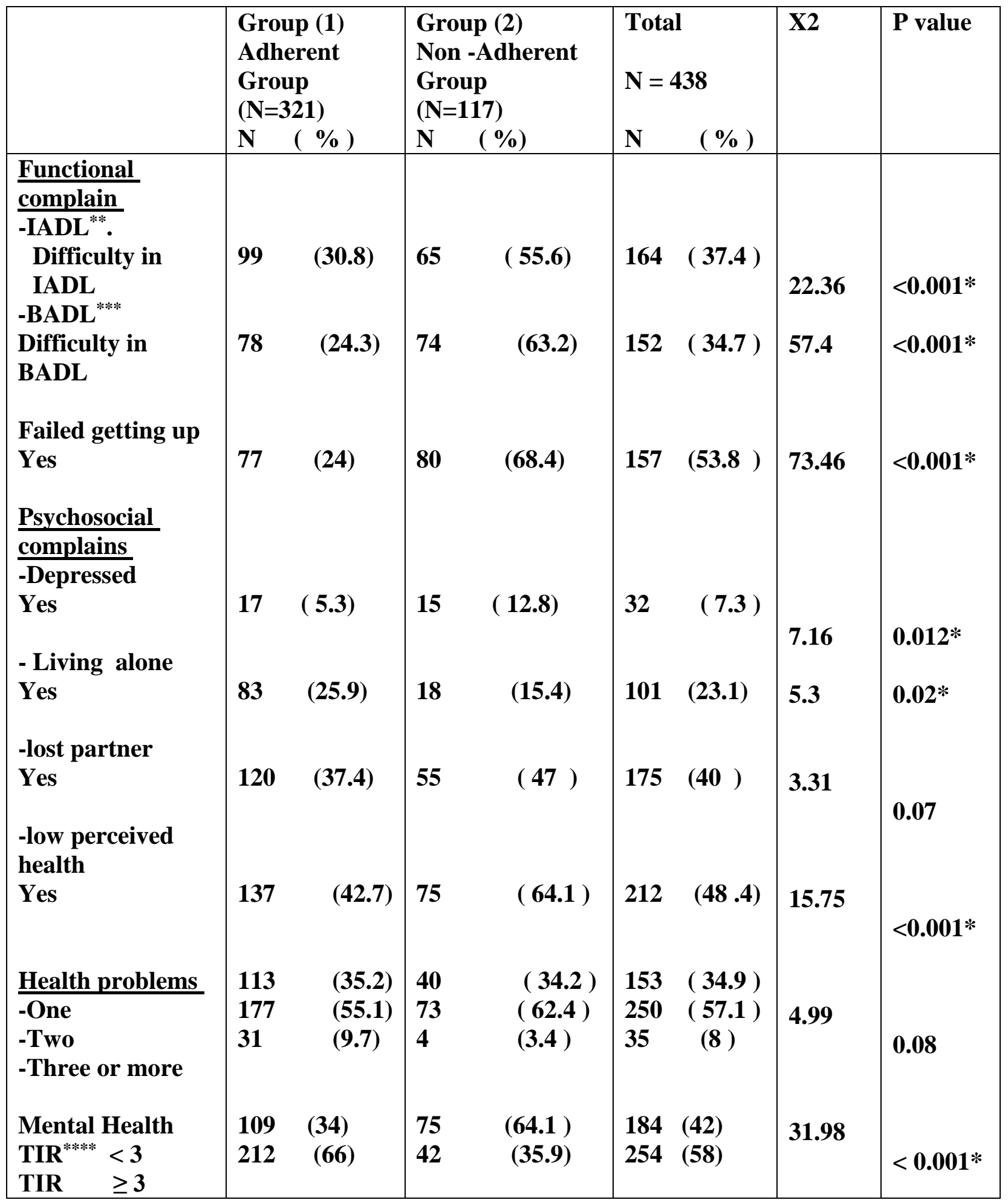

* $\mathrm{p}$ value is significant at $\mathrm{p}<0.05$ and highly significant at $<0.001$

**IADL : Instrumental Activity of Daily Living

****BADL : Basic Activity of Daily living 
***** Three Item Recall

Table (3) : Medications parameters as determinants of adherence of geriatric patients to their medications :

\begin{tabular}{|c|c|c|c|c|c|}
\hline & $\begin{array}{l}\text { Group (1) } \\
\text { Adherent } \\
\text { Group } \\
(\mathbf{N}=321) \\
\text { N } \quad(\%)\end{array}$ & $\begin{array}{l}\text { Group (2) } \\
\text { Non - } \\
\text { Adherent } \\
\text { Group } \\
(\mathbf{N}=117) \\
\text { N (\%) }\end{array}$ & $\begin{array}{l}\text { Total } \\
\mathrm{N}=438 \\
\mathrm{~N} \quad(\%)\end{array}$ & $\mathbf{X}^{2}$ & P value \\
\hline $\begin{array}{l}\text { Price of the drug } \\
\text { Cheap } \\
\text { Fair } \\
\text { Expensive } \\
\frac{\text { Number of }}{\text { prescribed drugs }} \\
<=3 \\
>3 \\
\text { Health Insurance } \\
\text {-Governmental } \\
\text {-primary care } \\
\text {-private }\end{array}$ & $\begin{array}{ll}58 & (18.1) \\
226 & (70.4) \\
37 & (11.5) \\
& \\
& \\
244 & (76) \\
77 & (24) \\
& \\
168 & (52.3) \\
45 & (14) \\
108 & (33.6)\end{array}$ & $\begin{array}{cc}31 & (26.5) \\
66 & (56.4) \\
37 & (11.5) \\
& \\
& \\
104 & (88.9) \\
13 & (11.1) \\
& \\
& \\
52 & (44.4) \\
32 & (27.4) \\
33 & (28.2)\end{array}$ & $\begin{array}{ll}57 & (13) \\
292 & (66.7) \\
89 & (20.3) \\
& \\
& \\
348 & (79.5) \\
90 & (20.5) \\
& \\
& \\
220 & 50.2) \\
77 & (17.6) \\
141 & (32.2)\end{array}$ & 8.07 & $\mathbf{0 . 0 3}^{*}$ \\
\hline
\end{tabular}


Fig ( 1 ) : Prevalence of medications adherence in the studied geriatric patients :

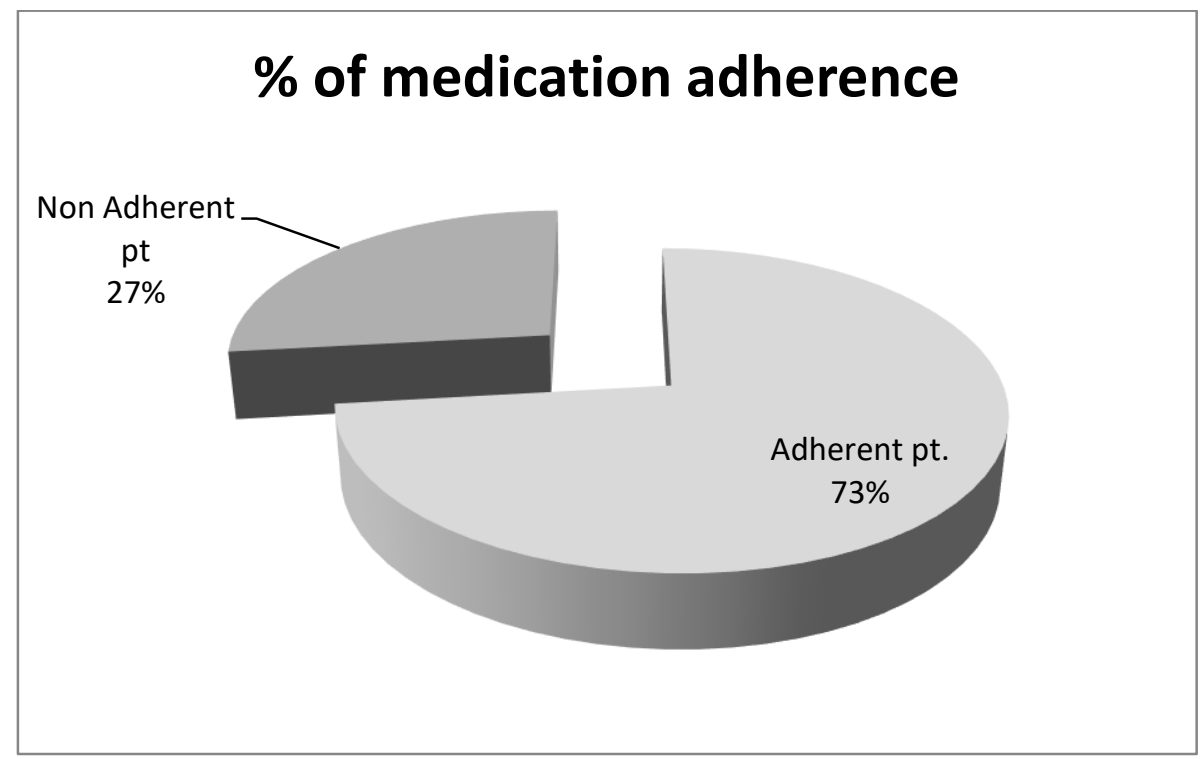

Fig ( 2 ) : Effect of patient satisfaction from their medications on their medication adherence score :

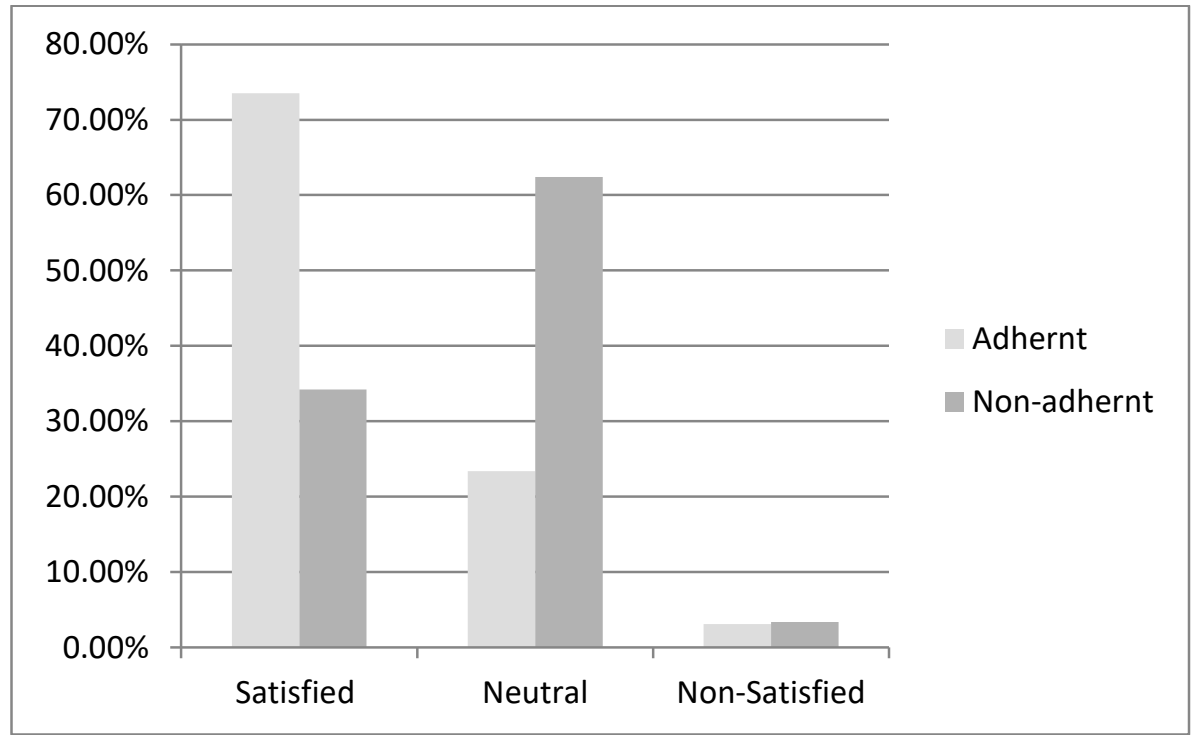

